\title{
GIS-based techniques for urban heat island spatialization
}

\author{
Mariusz Szymanowski* , Maciej Kryza
}

Institute of Geography and Regional Development, University of Wrocław, Pl. Uniwersytecki 1, 51-137 Wrocław, Poland

\begin{abstract}
This paper addresses the issue of usefulness of selected spatialization techniques for the characterization of an urban heat island (UHI). Five interpolation methods (including both deterministic and stochastic methods or their combination) - namely: inverse distance weighting (IDW), regularized spline with tension (RST), ordinary kriging (OK), multiple linear regression (MLR) and residual kriging $(\mathrm{RK})$ - were evaluated for their ability to estimate air temperature in Wrocław, Poland, during 7 cases of the UHI. Spatial interpolation was performed based on time-adjusted air temperature data gathered by mobile measurements. Additional explanatory variables for multidimensional spatialization methods (MLR and RK) were developed based mainly on the land-use map and Landsat thematic mapper (TM) images. Statistically significant predictors were selected using a stepwise regression procedure. Parameters for optimal interpolation were chosen by cross-validation (CV) of results. The CV technique was also used to compare results obtained with the different algorithms together with evaluation of errors (e.g. root mean square error, RMSE; mean absolute error, MAE) and visual examination of the final maps. The least plausible maps, both in terms of error statistics and visually, were obtained with the IDW method. Inside the convex hull of sample points, the OK and RST techniques were characterized by simplified but acceptable air temperature surfaces. The MLR method expressed the land-use background of the UHI, even outside the convex hull, but distorted results when the process tended towards non-stationarity, e.g. due to wind influence. The most accurate results of the UHI spatialization were obtained with the RK technique.
\end{abstract}

KEY WORDS: Spatialization · Spatial interpolation · Urban heat island · GIS · Wrocław Resale or republication not permitted without written consent of the publisher

\section{INTRODUCTION}

The development of GIS in recent years has been driven by the increase in the availability of digital spatial data as well as hardware and software capability and accessibility. Nowadays, spatial patterns of different phenomena can be analyzed and visualized using new tools and means of expression (e.g. 3D GIS), with the software becoming more effective year after year. Spatial interpolation techniques have been successfully introduced into the field of meteorology and climatology, where continuous spatial information on weather or climate is necessary (COST719 WG2 2006, Dobesch et al. 2007). In the context of spatial analysis, 'spatialization' can be understood as the transformation of point data (measurements) to derive new-or extend information from existing-geospatially referenced data, using different interpolation and extrapolation algorithms (COST719 WG2 2006). However, spatialization is usually used in the most general sense as equivalent to 'spatial interpolation'.

Urban heat islands (UHIs) are among the most common, although inadvertent, climatic changes caused by urbanization (Oke 1987). Studies on the differentiation of air temperature in urban areas date back to the first half of the 20th century (Peppler 1929, Middleton \& Millar 1936). The geomorphic analogy of UHIs to an island was confirmed by Oke (1976), who distinguished 3 zones of the UHI: the cliff, the plateau, and the peak where the maximum temperature is found. This general pattern is often disturbed by local changes in land-use types which may differ from the dominant category in a given zone. 
This means that the isothermal pattern of an UHI is generally concentric but also strongly dependent on the spatial arrangement of the land-use types that produce local variation. The UHI shape can therefore differ from city to city and may be described as 'amoebic' (e.g. Seoul, South Korea; Park 1986) or 'multicellular' (e.g. Łódź, Poland; Kłysik \& Fortuniak 1999).

Although knowledge on the origin and consequences of UHIs has gradually increased in recent years, the accurate estimation of the UHI spatial structure, which is often needed by town planners, is still one of the most important problems. In addition, air temperature determines numerous aspects of the urban environment and data on its spatial structure is an essential input for various modelling studies (e.g. dispersion of air pollutants). However, sampling sites in the monitoring system are often sparse, limiting the application of interpolation techniques. Data gathered at meteorological stations can be supported by mobile measurements to solve data inadequacy, although some data-time adjustments are needed (Duckworth \& Sandberg 1954, Kuttler et al. 1996, Unger et al. 2001, Szymanowski 2004).

The first attempts at spatial analysis of UHIs were based on isothermal maps calculated from mobile measurements (Duckworth \& Sandberg 1954, Park 1986, Moreno-Garcia 1994). Such interpolation has often been performed subjectively, using measurements from neighbouring points (stations) adjusted for representativeness, urban and terrain (elevation) factors affecting the local climate. Detailed information on interpolation techniques applied was not included in these previous papers and only a few studies were supported by more advanced mathematical tools (PrestonWhyte 1970, Clarke \& Peterson 1973). The development of GIS gave rise to a number of papers dealing with spatialization techniques and the UHI spatial structure (Svensson et al. 2002, Bottyán \& Unger 2003, Szymanowski 2004, Vicente-Serrano et al. 2005, Alcoforado \& Andrade 2006). Nowadays, computationally demanding methods are available and, more importantly, development of continuous information on potential UHI predictors, and sine qua non conditions for the use of multidimensional spatialization techniques, is feasible. Svensson et al. (2002), Vicente-Serrano et al. (2005), and Alcoforado \& Andrade (2006) present the results of UHI spatialization using different environmental (climate and terrain) information as potential predictors. The 'urban' group of UHI predictors used in spatial interpolation is related to various features characteristic of the urban environment (Bottyán \& Unger 2003, Szymanowski 2004, Szymanowski \& Kryza 2006). The main processes leading to UHI formation are well known and described (Oke 1982, 2006); roughness length (Grimmond \& Oke 1999) and sky view factor (SVF; Johnson \& Watson 1984) are among the main spatial parameters influencing UHI magnitude. Spatial information on roughness length and SVF are needed for multidimensional interpolation, but these can only be calculated if the proper input data are available (usually 3D buildings database; Ratti 2001, Lindberg 2007, Gal et al. 2008), which is not always the case (e.g. in Central and Eastern European countries).

The main goal of this paper is to examine the usefulness of selected spatialization algorithms for assessing the spatial pattern of air temperature during selected UHI occurrences in the city of Wrocław, SW Poland. The pros and cons of various interpolation algorithms are discussed in reference to UHI spatialization. Crossvalidation (CV) errors are compared, spatially presented and discussed.

\section{GENERAL CHARACTERISTICS OF THE UHI IN WROCEAW}

The city of Wrocław $\left(293 \mathrm{~km}^{2}\right.$; population 640 000) is located in SW Poland $\left(51^{\circ} \mathrm{N}, 17^{\circ} \mathrm{E}\right)$ at $\sim 120 \mathrm{~m}$ a.s.l. (Fig. 1). The altitude in the city area varies only from 105 to $148 \mathrm{~m}$ a.s.l., thus the temperature field is practically unaffected by elevation. Wrocław is situated along the Odra River. Approximately $31.4 \%$ of the city area is built-up, mainly with housing estates, industrial and warehouse buildings. The rest of the area consists of urban green space $(36.6 \%)$, agricultural areas $(28.9 \%)$ and water $(3.1 \%)$. The environmental conditions make Wrocław a good study site for a relatively undisturbed urban climate and for verification of urban climate models (Szymanowski 2004, 2005).

Research on the climate of Wrocław has been conducted since 1997 based on measurements of meteorological elements performed at automatic weather stations located in different areas of development and land-use type (Fig. 1) as follows: (Stn U) city centre, densely built-up area, up to 5 storeys; (Stn B) housing estates, 5 to 11 storeys; (Stn Re) dispersed, residential development, up to 3 storeys; and (Stn R) rural (agriculture, meadow and brushwood) area at the perimeter of the city (Szymanowski 2004, 2005).

The magnitude, frequency of occurrence and spatiotemporal characteristics of the UHI in Wrocław are like those observed in similarly populated and located European and North American cities, and were described earlier by Szymanowski (2004, 2005). Here, only a brief description is given for clarity.

The annual mean magnitude of the heat island in the centre of Wrocław reaches $1.0 \mathrm{~K}$. It is calculated as the difference in air temperature (dT) between urban $(\mathrm{U}, \mathrm{B}, \mathrm{Re})$ and rural (R) stations, based on hourly data av- 


\begin{tabular}{|c|c|c|}
\hline Agricultural area & $\square$ & Base stations \\
\hline Urban greenspace & $\circ$ & Mobile measurements \\
\hline Industrial area & & \\
\hline Housing development & & \\
\hline Water & & \\
\hline
\end{tabular}

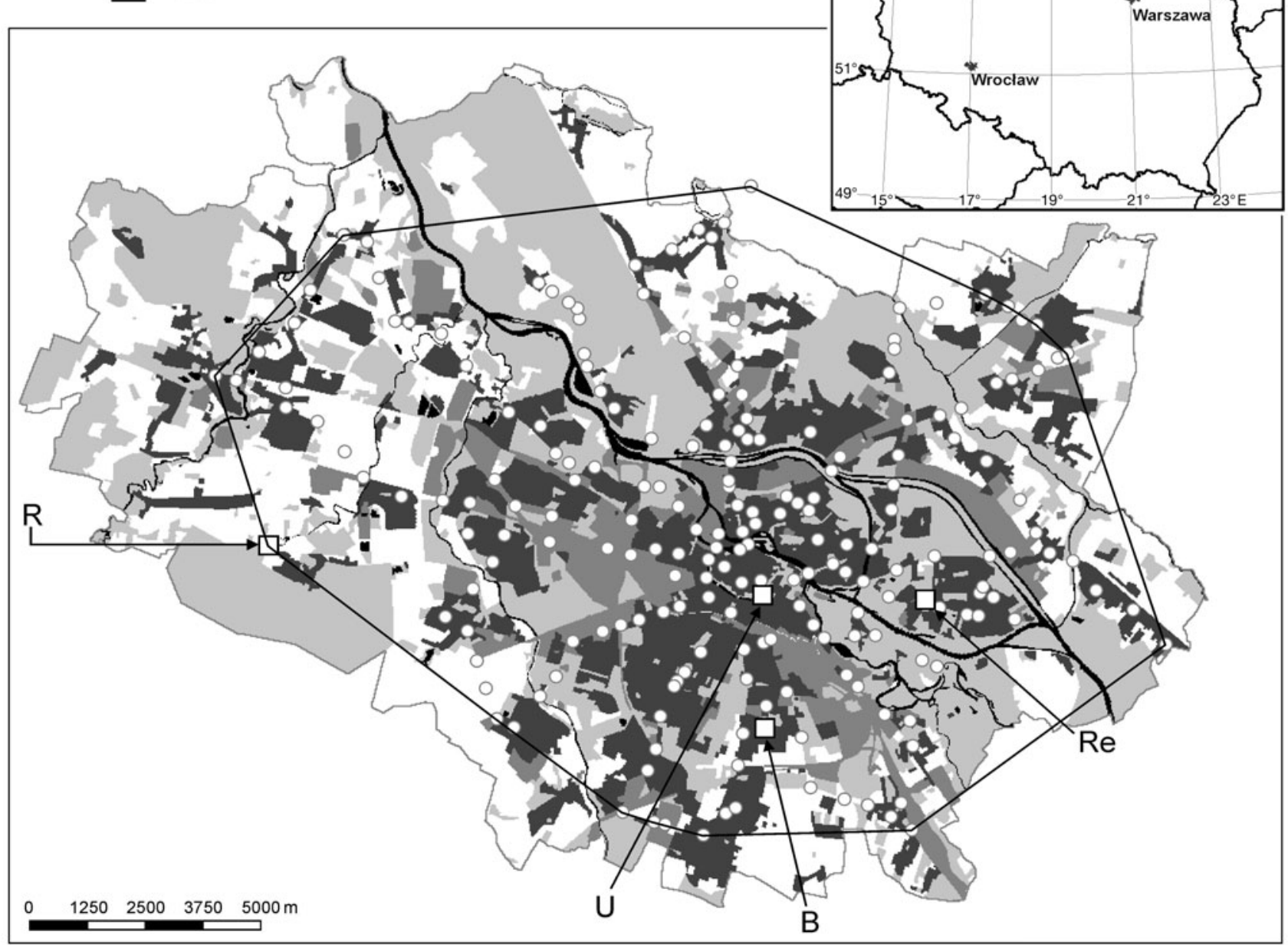

Fig. 1. Land-use map of Wrocław, air temperature measurement sites (see Section 2 for abbreviations) and convex hull (black perimeter line)

eraged for the period April 1997 - March 2000 (Table 1). Thermal excess reaches the highest value in the densely built-up central part of the city and is lower in large housing estates of tall concrete buildings $(0.7 \mathrm{~K})$ or in residential areas of low estate houses $(0.3 \mathrm{~K})$. At night, the UHI magnitude in compact settlements and housing estates with tall buildings may be 2 or 3 times higher than the average values for daytime, the latter not exceeding 0.5 K (average for April 1997 to March 2002), irrespective of the settlement type (Table 1).

In the period April 1997 to March 2000, the maximum instantaneous magnitude of the UHI in the centre of Wrocław reached $8.4 \mathrm{~K}$ (10 Feb 1999; 20:00 h; Table 1), which seems to be typical for cities of this size (Kłysik \& Fortuniak 1999).
The UHI in Wrocław reaches the highest magnitude during nighttime. In the daytime, the maximum observed UHI may exceed $6.0 \mathrm{~K}$ (Table 1 ). The minimum values of $\mathrm{dT}_{\mathrm{U}-\mathrm{R}}$ (the difference in temperature between U and R stations; almost $-4.0 \mathrm{~K}$ ) may occur both during the day and night. Situations when the city centre is cooler than areas outside the city, the so-called 'cool islands' (Jauregui 1986), can be observed in $\sim 12 \%$ of hours in a year. Positive values of $\mathrm{dT}_{\mathrm{U}-\mathrm{R}}$ in the city centre are observed during $>96 \%$ of night hours and $>80 \%$ of daytime. Highest intensities (>5.0 K) of the UHI are observed in $3.8 \%$ of night hours and only in a few cases during daytime. Strong daytime UHI events are caused by thermal advections in frontal zones passing over the city (Szymanowski 2005). 
Table 1. Magnitude and frequency of the UHI in the different land-use types of Wrocław during April 1997 to March 2000. dT: difference in temperature. See Section 2 for further (subscripted) abbreviations

\begin{tabular}{|lrrrrrrr|}
\hline & \multicolumn{3}{c}{ Magnitude $(\mathrm{K})$} & \multicolumn{5}{c|}{ Frequency (\%) } \\
& Avg & Max & Min & $>0.5 \mathrm{~K}$ & $>1.0 \mathrm{~K}$ & $>3.0 \mathrm{~K}$ & $>5.0 \mathrm{~K}$ \\
\hline City centre $\left(\mathrm{dT}_{\mathrm{U}-\mathrm{R}}\right)$ & & & & & & & \\
$\quad$ Night & 1.6 & 8.4 & -3.9 & 77.1 & 50.6 & 15.5 & 3.8 \\
Day & 0.5 & 6.4 & -3.7 & 27.6 & 17.3 & 2.0 & 0.3 \\
Housing estate $\left(\mathrm{dT}_{\mathrm{B}-\mathrm{R}}\right)$ & & & & & & & \\
$\quad$ & 1.1 & 9.0 & -3.8 & 77.1 & 38.6 & 9.9 & 1.7 \\
Night & 0.3 & 6.5 & -4.9 & 27.6 & 11.2 & 1.1 & 0.1 \\
Day & & & & & & \\
$\quad$ Night & 0.4 & 6.2 & -4.8 & 77.1 & 18.0 & 1.1 & 0.1 \\
Day & 0.2 & 6.4 & -4.4 & 27.6 & 7.9 & 0.20 & 0.0 \\
\hline
\end{tabular}

The annual cycle of the UHI magnitude is closely related to meteorological conditions and emissions of artificial heat. In the centre of Wrocław, the highest values of the average UHI magnitude are observed in the warm season, mainly in spring (May: $1.3 \mathrm{~K}$; Fig. 2). The minimum value of $0.8 \mathrm{~K}$ is noted in autumn (October). Despite the increase in the average degree of cloud cover and wind speed in winter months, an increase in the UHI magnitude is noted due to larger emissions of artificial heat during the heating season (Szymanowski 2004).

The most influential factors affecting UHI magnitude are wind speed and cloudiness, the former having a direct impact on energy exchange through turbulence, and the latter modifying radiation exchange. In Wrocław, an increase in wind speed to $>4 \mathrm{~m} \mathrm{~s}^{-1}$ at night and $1 \mathrm{~m} \mathrm{~s}^{-1}$ during the daytime, irrespective of the cloudiness, eliminates the UHI or considerably reduces its magnitude (below 1.0 Ki Szymanowski 2005). The impact

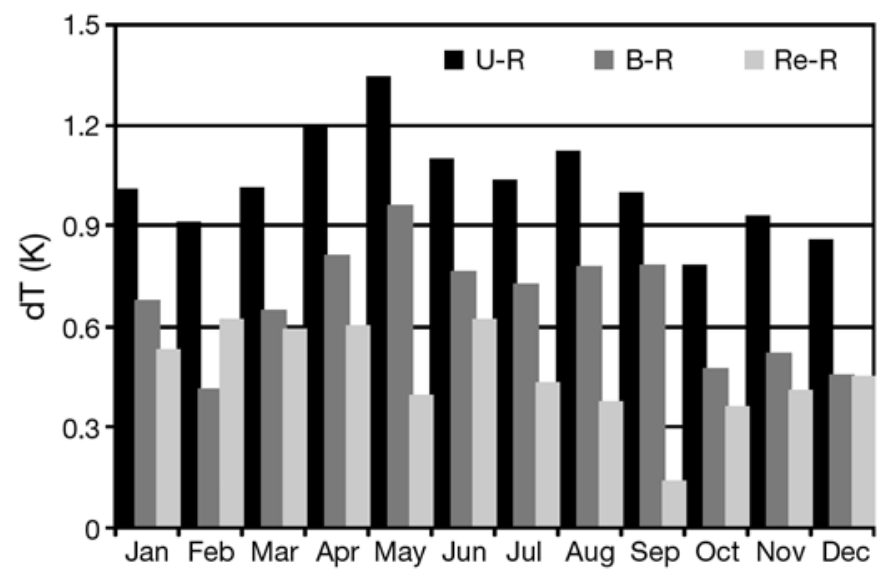

Fig. 2. Mean annual course of urban-rural air temperature differences $\left(\mathrm{dT}_{\mathrm{U}-\mathrm{R}}, \mathrm{dT}_{\mathrm{B}-\mathrm{R}}, \mathrm{dT}_{\mathrm{Re}-\mathrm{R}}\right)$ for Wrocław, April 1997 March 2000. See Section 2 for a description of station abbreviations, and Fig. 1 for station locations of cloudiness is practically unnoticeable during daytime. At night, however, an increase in cloudiness above 6 oktas diminishes the UHI magnitude (Szymanowski 2005).

\section{DATA AND METHODS}

The project encompassed 4 main stages (Fig. 3): (1) air temperature measurements and pre-processing, presented in Section 3.1; (2) preparation of digital spatial information (Section 3.2); (3) application of various spatialization algorithms for the selected UHI cases (Section 3.3) and evaluation of the results (Section 4); and (4) visual and quantitative evaluation of the interpolation results (Section 4).

$\mathrm{R}$ statistical software ( $\mathrm{R}$ Development Core Team 2007) with gstat library (Pebesma 2004) and the GIS GRASS system (GRASS Development Team 2007) were used for the statistical analysis, spatialization and visualization of the results.

\subsection{Meteorological data}

Air temperature data were collected using mobile measurements (car traverses) and automatic weather stations located in various land-use types as mentioned above (Fig. 1). The mobile measurements were performed with the automatic meteorological units mounted on 2 cars during the UHI stabilization phase to avoid rapid changes in UHI magnitude (HaegerEugensson \& Holmer 1999, Runnalls \& Oke 2000). Each car had a unique, $90 \mathrm{~km}$ route and was moving at an average speed of $30 \mathrm{~km} \mathrm{~h}^{-1}$; thus, each measuring session lasted for $\sim 3$ to $4 \mathrm{~h}$. The cars started and finished their routes at Stn Re. Temperature data were collected with radiation-shielded, aspirated resistance sensors (Pt-100) connected to the data logger. Temperature was measured every $5 \mathrm{~s}$ at $2 \mathrm{~m}$ above the ground (screen level). Data collected during imposed stops, e.g. at traffic lights, were rejected (Szymanowski 2004). Recorded data were corrected for temperature changes during the measurement session. Time adjustments were applied based on cooling rates, after the methodology proposed by Kuttler (1993). The whole area of the city was divided into 4 zones of different cooling rates according to 4 automatic weather stations located in different land-use classes. This method required generalization of the land-use map described in Section 3.2. Each measurement point was classified to one of the 4 zones and the temperature was adjusted 


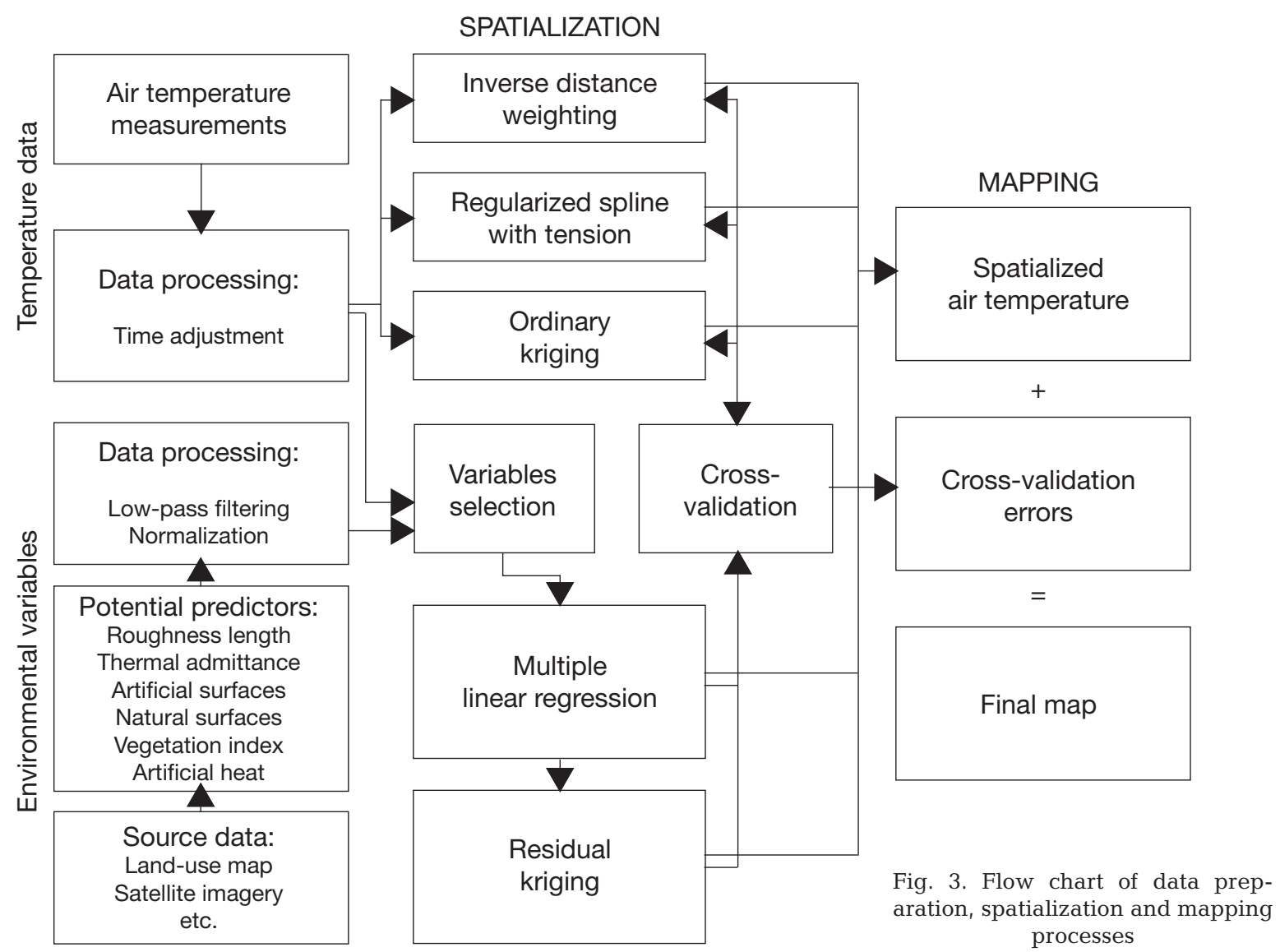

depending on time of measurement and the cooling rate value. Measurement points were systematically selected along routes to represent different land-use categories, with some densification over the most interesting and geometrically diverse areas in the city centre. Finally, for each UHI case analysed, the temperature values from 206 points were taken as the input data for the spatialization process (Figs. $1 \& 3$ ).

Air temperature measurements for the presented case study were done in 2001-2002 during 7 nights with relatively weak winds $\left(<4 \mathrm{~m} \mathrm{~s}^{-1}\right)$ and cloudless to moderately cloudy skies (Table 2). The mobile measurements in urban environments were usually performed during almost calm wind conditions that allowed measurement of UHI diversity and magnitude caused by urban and anthropogenic processes controlled by factors such as urban geometry, artificial heat emission, thermal properties of constructing materials etc. (Oke 1987). Previous studies on the UHI in Wrocław revealed that an increase in wind speed to $>4 \mathrm{~m} \mathrm{~s}^{-1}$ at night, irrespective of cloudiness, causes considerable reduction of the UHI magnitude (Szymanowski 2005). Therefore, wind speeds $<4 \mathrm{~m} \mathrm{~s}^{-1}$ may be considered as UHI-favourable in Wrocław. Of the cases analyzed, only one is characterized by wind speed exceeding $3 \mathrm{~m} \mathrm{~s}^{-1}$ (Table 2). The other sessions were taken during calm or almost calm conditions that caused distinct diversity of the UHI in magnitude (difference between maximum and minimum temperature $\mathrm{dT}_{\mathrm{M}} \geq 6.0 \mathrm{~K}$ ) and also in space (see Figs. 5 to 7 ). In each case, the strongest winds were observed at Stn R. In 6 of the 7 cases, general agreement of the prevailing wind direction on the west $(\mathrm{R})$ and east $(\mathrm{Re})$ side of the city was observed, suggesting a dominant role for the regional wind over a potential local UHI circulation. On 22 May 2001, opposite winds directed towards the city centre could be attributed to 'urban breeze', but this is not supported by the relevant measurements.

The UHI intensity calculated from the mobile measurements $\left(\mathrm{dT}_{\mathrm{M}}\right)$ is usually considerably higher than that calculated as $\mathrm{dT}_{\mathrm{U}-\mathrm{R}}$ (especially in the case of $15 \mathrm{Jan}$ 2002, Table 2). This may be attributed to the location of the urban station $(\mathrm{U})$ in the peak zone, but not exactly in the warmest area due to technical reasons.

\subsection{Explanatory variables for UHI spatialization}

The UHI is usually observed during calm and cloudless atmospheric conditions as a result of energetic exchange depending on many processes and characteristics of urban areas (Oke 1982, Oke et al. 1991). 
Table 2. Meteorological conditions, UHI magnitude in the city centre $\left(\mathrm{dT}_{\mathrm{U}-\mathrm{R}}\right)$ and the difference $\left(\mathrm{dT}_{\mathrm{M}}\right)$ between maximum and minimum temperature at the measurement points (after time adjustment) for the selected cases. UTC: coordinated universal time

\begin{tabular}{|c|c|c|c|c|c|c|c|}
\hline \multirow[t]{2}{*}{ Date } & \multirow{2}{*}{$\begin{array}{l}\text { Time } \\
\text { (UTC) }\end{array}$} & \multirow{2}{*}{$\begin{array}{l}\text { Wind speed } \\
\text { Stn R } \\
\left(\mathrm{m} \mathrm{s}^{-1}\right)\end{array}$} & \multicolumn{2}{|c|}{ Prevailing wind direction } & \multirow{2}{*}{$\begin{array}{c}\text { Cloudiness } \\
\text { Stn R } \\
\text { (oktas) }\end{array}$} & \multirow{2}{*}{$\begin{array}{c}\mathrm{dT}_{\mathrm{U}-\mathrm{R}} \\
(\mathrm{K})\end{array}$} & \multirow{2}{*}{$\begin{array}{r}\mathrm{dT}_{\mathrm{M}} \\
(\mathrm{K})\end{array}$} \\
\hline & & & Stn R & Stn Re & & & \\
\hline 22 May 2001 & 00:00 & $0-1$ & W to WSW & ENE to E & 0 & 6.0 & 8.3 \\
\hline 26 Jun 2001 & 00:00 & $0-1$ & W to SSW & $\mathrm{S}$ & $0-3$ & 4.9 & 6.6 \\
\hline 30 Jul 2001 & $22: 30$ & $1-2$ & SW to WSW & S to SSW & $1-4$ & 3.8 & 7.3 \\
\hline 13 Oct 2001 & $21: 30$ & $1-2$ & $\mathrm{~N}$ to NW & NE & 0 & 3.4 & 7.7 \\
\hline 03 Jan 2002 & 02:00 & $0-1$ & $\mathrm{~N}$ to $\mathrm{NNE}$ & NE to ENE & $0-2$ & 6.2 & 9.0 \\
\hline 15 Jan 2002 & 01:00 & $3-4$ & ESE to SE & E & 0 & 0.7 & 3.6 \\
\hline 15 Feb 2002 & $00: 30$ & $1-3$ & NE to ENE & ENE & 0 & 1.9 & 6.0 \\
\hline
\end{tabular}

The most important factors influencing UHI formation and its magnitude are: the introduction of new surface materials, the expansion of active urban surfaces (geometry) and the emission of artificial heat, moisture and air pollutants. These features change the aerodynamic, radiative, thermal and moisture conditions that are responsible, among others, for alteration of the air temperature field over the city. Some parameters characterizing size, geometry and 'metabolism' of cities may be directly or indirectly derived from maps, digital databases and satellite images with GIS techniques. Such approximated derivatives can then be used in spatial interpolation as additional explanatory variables determining the UHI spatial structure in the urban canopy layer (Bottyán \& Unger 2003, Szymanowski 2004, Alcoforado \& Andrade 2006, Szymanowski \& Kryza 2006).

In this study, a set of potentially significant predictors for the UHI phenomenon was established. Parameters considering the impact of terrain relief on temperature were assumed to be negligible due to the lack of significant elevation changes in Wrocław. All auxiliary variables were derived from the digital land-use map (16 land-use classes, 10 for built-up and 6 for nonbuilt-up areas, $25 \mathrm{~m}$ resolution) supported by the buildings database (perimeters, heights and spatial arrangement) available only for the selected areas of the city, topographic maps (scale 1:10000), orthophotomap and $30 \mathrm{~m}$ (60 $\mathrm{m}$ for near infrared band) resolution Landsat thematic mapper (TM) imagery covering Wrocław and its surroundings. Because consistent information on building parameters was not directly available for the whole city, an indirect method of land-use classes parameterization was applied. Three testing areas of $\sim 9$ ha each were assigned for every land-use category. For these testing fields, the buildings database was prepared based on local government database, checked and corrected using field measurements. Average values of parameters derived from these source data were assumed to be typical for a given land-use category (Table 3 ).
Finally, a set of 6 parameters, all strongly correlated with air temperature, was used for the multidimensional interpolation of the UHI. These are:

(1) Roughness length $\left(z_{0} ; \mathrm{m}\right)$ which is calculated using the modified formula proposed by Lettau (1969). Due to limited information on buildings geometry, some simplifications are assumed. The lot area is held equal to the area of the given land-use class and wind direction is not incorporated in the silhouette parameter. Central parts of the city are characterized by values reaching $3.7 \mathrm{~m}$, exceeding $7.0 \mathrm{~m}$ only in the vicinity of the highest buildings (Table 3 ). Leaving the central part, a gradual decrease of $z_{0}$ to $0.5-1.0 \mathrm{~m}$ in residential areas and $<0.5 \mathrm{~m}$ in the rural zone can be observed. This is consistent with values calculated for other cities by Oke (1987) and Fortuniak (2003).

(2) Percentage of artificial surfaces (AS) in a given land-use class. Both horizontal (roofs, roads, parking lots, pavements, etc.) and vertical surfaces (walls) are taken into account. Artificial surfaces are added together and linked to the lot area. Buildings are represented by boxes and roof structures are not considered during calculations. AS values exceed $200 \%$ in densely built-up areas of the city centre, decreasing to $\sim 100 \%$ in the housing estates, $<70 \%$ in residential and $<10 \%$ in rural areas (Table 3 ).

(3) Percentage of non-built-up surfaces (NS) in a given land-use class. Calculations for this parameter are similar to those for AS, but only horizontal surfaces are considered. For some land-use classes (densely built-up, industrial areas), this factor does not exceed $10 \%$ but reaches 90 to $95 \%$ in the rural zone (Table 3 ).

(4) Normalized difference vegetation index (NDVI), calculated directly from the near infrared and red bands of Landsat TM for each raster element (Tucker 1979). Calculations of NDVI for a given pixel always result in a number that ranges from -1 to +1 . Zero means no vegetation and values close to $+1(0.8-0.9)$ indicate the highest possible density of green leaves. In this case, the calculations of NDVI are performed based on Landsat images taken in summer (August). 
Table 3. Values of selected urban parameters attributed to different land-use categories. s.: season; st: stories. See Section 3.2 for abbreviations

\begin{tabular}{|c|c|c|c|c|c|c|c|}
\hline Land-use class & $\begin{array}{c}z_{0} \\
(\mathrm{~m})\end{array}$ & $\begin{array}{l}\text { AS } \\
(\%)\end{array}$ & $\begin{array}{l}\text { NS } \\
(\%)\end{array}$ & $\begin{array}{l}\text { NDVI } \\
\text { mean }\end{array}$ & $\begin{array}{c}\mu \\
\left(\mathrm{J} \mathrm{m}^{-2} \mathrm{~s}^{-1 / 2} \mathrm{~K}^{-1}\right)\end{array}$ & $\begin{array}{c}Q_{A}\left(\mathrm{~W} \mathrm{~m}^{-2}\right) \\
\text { non-heating s. }\end{array}$ & $\begin{array}{l}Q_{A}\left(\mathrm{~W} \mathrm{~m}^{-2}\right) \\
\text { heating s. }\end{array}$ \\
\hline Densely built-up area, up to 5 st. & 3.70 & 200 & 10 & 0.07 & 1754 & 25 & 100 \\
\hline Buildings higher than 11 st. & 7.40 & 250 & 50 & 0.14 & 1675 & 25 & 100 \\
\hline Housing estate, 5-11 st. & 2.40 & 100 & 70 & 0.20 & 1524 & 22 & 80 \\
\hline Housing estate, up to 5 st. & 2.30 & 120 & 45 & 0.19 & 1597 & 20 & 75 \\
\hline Residential area, high intensity & 1.00 & 70 & 70 & 0.22 & 1448 & 18 & 50 \\
\hline Residential area, less intensity & 0.50 & 50 & 85 & 0.29 & 1402 & 15 & 40 \\
\hline Industrial area & 2.10 & 100 & 15 & 0.16 & 1699 & 20 & 70 \\
\hline Shopping centre & 2.10 & 100 & 15 & 0.06 & 1699 & 20 & 70 \\
\hline Railway area & 0.50 & 90 & 10 & 0.23 & 1719 & 5 & 10 \\
\hline Parking lot & 0.05 & 90 & 10 & 0.11 & 1719 & 5 & 10 \\
\hline Agricultural area & 0.10 & 2 & 98 & 0.27 & 938 & 0 & 0 \\
\hline City forest & 1.00 & 0 & 100 & 0.48 & 1182 & 0 & 0 \\
\hline Park, cemetery & 1.00 & 2 & 98 & 0.36 & 1182 & 0 & 0 \\
\hline Garden & 0.50 & 5 & 95 & 0.35 & 1090 & 0 & 0 \\
\hline Meadow & 0.10 & 0 & 100 & 0.37 & 938 & 0 & 0 \\
\hline Water & 0.01 & 0 & 100 & 0.12 & 1553 & 0 & 0 \\
\hline
\end{tabular}

Mean values of NDVI vary from 0.06 to 0.29 for builtup classes, from 0.27 to 0.48 for non-built-up classes, and 0.12 for water (Table 3 ).

(5) Thermal admittance $\left(\mu ; \mathrm{J} \mathrm{m}^{-2} \mathrm{~s}^{-1 / 2} \mathrm{~K}^{-1}\right)$, estimated as a weighted value using the ratio of vegetated surfaces to artificial surfaces. Thermal admittance for concrete (built-up classes) and moderately moist (40\%) clay soil covered by grass (non-built-up classes excluding water) are used as starting values, after Boeker \& van Grondelle (1995). The parameter values change from $<950 \mathrm{~J} \mathrm{~m}^{-2} \mathrm{~s}^{-1 / 2} \mathrm{~K}^{-1}$ for meadows, to $>1750 \mathrm{~J} \mathrm{~m}^{-2}$ $\mathrm{s}^{-1 / 2} \mathrm{~K}^{-1}$ for the city centre (Table 3 ), which is consistent with other estimates (Oke 1982, Fortuniak 2003).

(6) Anthropogenic heat emission $\left(Q_{A} ; \mathrm{W} \mathrm{m}^{-2}\right)$ from the urban units of Wrocław. $Q_{A}$ was earlier estimated by Chudzia \& Dubicka (1998) for the Wrocław area based on detailed inventory of energy consumption in the late 1990s. Electric energy and fuel consumption for residential heating were used to estimate artificial heat release during non-heating (Apr to Oct) and heating (Nov to Mar) seasons in various parts of the city and in various land-use classes. Mean annual heat flux for the central parts of the city was estimated at $62.5 \mathrm{~W}$ $\mathrm{m}^{-2}$, reaching $100 \mathrm{~W} \mathrm{~m}^{-2}$ in the heating season. Values of $Q_{A}$ for the heating season are 2 to 4 times greater than those for the non-heating season and vary from 10 to $100 \mathrm{~W} \mathrm{~m}^{-2}$ depending on land-use category (Table 3). $Q_{A}$ for non-built-up classes is set at zero.

Given a set of values approximated for each parameter and land-use category, the land-use map was reclassified and the categories replaced with quantities (Table 3).

The portion of the surroundings which is 'seen' by the sensor placed above the ground surface at a known height is referred to as the 'source area'. In the case of air temperature, the shape and size of the source area depends upon turbulent transport and is normally elliptical and aligned in the upwind direction from the sensor. However, under windless meteorological conditions, the shape of the source area is approximately circular. The estimation of the source area can best be applied in the inertial sublayer, above the complications of the roughness sublayer and the complex geometry of the 3D urban surface. Within the urban canopy, the source area cannot be reliably evaluated but can be estimated to have a radius of $\sim 0.5 \mathrm{~km}$ (screen level rule-of-thumb, after Oke 2004), depending on building density. Therefore, a set of raster layers for each parameter was developed with low-pass filtering (Fig. 3). For each grid square, the filter calculates the average of the values within a specified neighbourhood of the input raster map. The averaging reduces isolated high values and smoothes sharp gradients on the boundary of the original land-use classes. The averaging matrices applied here are circular in shape with radii varying from 50 to $1000 \mathrm{~m}$.

\subsection{Spatialization algorithms}

Both stochastic and deterministic interpolation algorithms (and their combinations) were used in this study. Stochastic (geostatistical) interpolators are based on probability theory and spatial autocorrelation of geographical data (Cressie 1991). The mathematical, deterministic methods are usually physically based, providing the opportunity to explain and predict a variable at each point according to the known physical processes causing the spatial variation of the spatialized phenomena (Ustrnul \& Czekierda 2005). Further, 
spatialization techniques can be subdivided into local and global algorithms. The latter use all available data to make a prediction for the entire area, whereas the former operate within a defined zone using data from the direct neighbourhood of the point being estimated. Spatialization methods may also be exact or inexact, depending on whether they preserve the measured value at the location of the measurement or not. Inexact methods tend to remove local variation in order to minimize predictive errors across the whole domain. Finally, some algorithms can be considered as 'multidimensional' as they make use of additional explanatory, georeferenced variables (spatially continuous predictors).

Choosing the optimal spatial interpolator for the UHI is particularly difficult because of the heterogeneous nature of urban areas where large local gradients in temperature may appear due to changes in land-use type, SVF and other influencing factors. In this study, 5 spatialization methods, based on different theoretical backgrounds (local and global perspective, deterministic and stochastic nature), were compared:

(1) Inverse Distance Weighting (IDW) is a widely applied mathematical method of spatial interpolation. The value at a certain point is calculated as a weighted sum of the values at nearby measurements. The weights are proportional to the inverse of the distance between the interpolated and measured points. Mathematically, the IDW can be expressed as:

$$
Z_{j}^{*}=\frac{\sum_{i=1}^{n} \frac{1}{d_{i j}^{\beta}} Z_{i}}{\sum_{i=1}^{n} \frac{1}{d_{i j}^{\beta}}}
$$

where $Z_{j}^{*}$ is an estimated value at point $j, Z_{i}$ is a known value at point $i, d_{i j}$ is the distance between the point to be estimated $(j)$ and neighbouring points $(i)$, and $\beta$ is the weighting power, equal to 2 in this study. The CV method is performed to determine the optimum $\beta$ value for IDW interpolation, with the $\beta$ changing from 0.5 to 3.5 (0.5 increment). The largest CV errors were obtained for the small weighting powers $(\beta<1)$, while the smallest CV errors were obtained for $\beta=2$, increasing slightly for $\beta>2$. In this study, the IDW algorithm implemented in the gstat library (Pebesma 2004) was used.

(2) Regularized Spline with Tension (RST) is a deterministic method to represent 2D curves on 3D surfaces (Mitašova \& Mitaš 1993). The interpolation is made flexible through the choice of the tension parameter which controls the properties of the function and the smoothing parameter, allowing noise filtering. If the smoothing parameter is not used, the resulting surface tends to have a wave pattern that fulfills the criterion of exact estimation. It may result in an odd spatial pattern and invalid values can be obtained (Dobesch et al. 2007). The general formula for the RST is:

$$
Z_{j}^{*}=T_{j}+\sum_{i=1}^{n} \lambda_{i} R\left(d_{i j}\right)
$$

where $Z_{j}^{*}$ is as defined in Eq. (1), $T_{j}$ and $\lambda_{i}\left(\lambda_{1}, \ldots, \lambda_{n}\right)$ are $n+1$ parameters calculated by solving a system of $\mathrm{n}+1$ equations and $R\left(d_{i j}\right)$ is a radial basis function (Mitašova \& Mitaš 1993), which also includes the tension and smoothing parameters mentioned above. In this study, RST implementation available through the GIS GRASS system was used (Mitašova \& Mitaš 1993).

(3) Ordinary Kriging (OK) is a group of stochastic methods that incorporate the concept of randomness in spatial processes. They are based on the assumption that values measured at neighbouring locations tend to be more alike than values measured at remote sites. A variogram or covariance function is used as a tool for quantifying the spatial autocorrelation of data. Kriging uses a linear combination of weights derived through the semivariogram modeling procedure. In the first step, the experimental semivariogram $\gamma(r)$ is estimated from the measured data, using one of numerous estimators such as the classical semivariogram estimator (Cressie 1991):

$$
\gamma(r)=\frac{1}{2|N(r)|} \sum_{N(r)}\left[Z\left(s_{i}\right)-Z\left(s_{j}\right)\right]^{2}
$$

where $r$ is a distance vector between locations $S_{i}$ and $s_{j}, N(r)$ denotes the set of pairs of locations at distance $r$, and $|N(r)|$ is the number of corresponding pairs of locations. A theoretical semivariogram model (spherical, exponential, etc.) is fitted to the values of the experimental semivariogram. The theoretical variogram model is defined by the range (the longest distance with correlated values of the random process), the sill (the variance of random process) and the nugget that represents microscale variation. The spatial process is assumed to be intrinsically stationary. The prediction of the OK is a weighted linear combination of the available data. Linear coefficients $(\lambda)$ are calculated under the condition of a uniformly unbiased predictor $\left(\sum_{i=1}^{n} \lambda_{i}=1\right)$ and under the constraint of minimal prediction error variance. The OK predicted value $Z^{*}\left(s_{0}\right)$ for the location $s_{0}$ can be expressed as:

$$
Z^{*}\left(s_{0}\right)=\sum_{i=1}^{n} \lambda_{i} Z\left(s_{i}\right)
$$

A detailed description of the method can be found in Cressie (1991). In this study, a spherical model of the semivariogram was incorporated.

(4) Multiple Linear Regression (MLR) was used in this study as a deterministic procedure (Dobesch et al. 
2007). Thus, the independent variables (predictors) can be physically explained considering processes responsible for UHI formation. Mathematically, it is expressed by the equation:

$$
Z(s)=\beta_{0}+\sum_{i=1}^{n} \beta_{i} X_{i}
$$

where $Z(s)$ is the interpolated variable, $X_{1}, \ldots, X_{n}$ are explanatory (independent) variables, and $\beta_{0}, \ldots, \beta_{n}$ are coefficients of linear regression. MLR is one of the few multidimensional interpolation schemes which are used in modern climatology (Ninyerola et al. 2000, Ustrnul \& Czekierda 2005). The MLR method has been used for macro- or regional-scale interpolation (Ninyerola et al. 2000, Ustrnul \& Czekierda 2005). The first attempts showed that this approach may also be applied to local-scale studies (Szymanowski 2004, Szymanowski \& Kryza 2006).

(5) Residual Kriging (RK) is kriging under the trend model group (universal kriging, residual kriging, kriging with external drift) where a random function is modeled as the sum of a trend component (drift) plus a residual (Dobesch et al. 2007). In the MLR approach described above (Eq. 5), there is a part of the variation which is not explained by the regression model (residual) referred to as $\delta(s)$ as shown in a modification of Eq. (5) below:

$$
Z(s)=\beta_{0}+\sum_{i=1}^{n} \beta_{i} X_{i}+\delta(s)
$$

The residuals are assumed to be a random variable that follows the intrinsic hypothesis, and values of $\delta(s)$ are usually interpolated with the OK method. In the RK algorithm, the spatial pattern of the interpolated variable is calculated as the sum of the MLR-derived layer (deterministic part) and the spatially interpolated regression residuals (stochastic part): $Z^{*}(s)+\delta(s)$.

The starting parameters for the IDW, RST and OK spatialization methods were obtained by the $\mathrm{CV}$ procedure using the criterion of minimal errors (Fig. 3). This was done to ensure that the results obtained for a given interpolation algorithm did not suffer from wrong parameterization, i.e. that only the best possible results calculated with a given spatialization method were compared with other algorithms. For each interpolation procedure, different values of the initial parameters were used and CV errors were evaluated. For the IDW, the power parameter and 'cut off' distance were set, while tension and smoothing parameters were set for the RST (Table 4). For the OK, an empirical semivariogram was prepared and a semivariogram model was built by selecting the best sill and range values through the CV procedure (Fig. 3). The spherical variogram model was selected, with no nugget and anisotropy effects allowed.

The MLR method was applied in this study to quantitatively describe the relations between measured air temperature and one or more spatially continuous predictors. Statistically significant predictors were selected for each UHI case from the set of environmental variables described in Section 3.2. Parameters for the MLR equation were calculated by least squares estimation. Selection of the predictors was performed stepwise, taking into account their statistical significance, their intercorrelation with other independent variables, and the Akaike Information Criterion (Hurvich et al. 1998). Also, the direction of dependence $(+$ or $-\beta)$ between the modeled air temperature and the statistically significant independent variable was checked to ensure that the final equation may be explained in terms of known physical processes that influence UHI formation.

The quality of each spatialization technique applied in this study was evaluated using the CV approach in which a single observation is removed from the original sample dataset and used as the validation data, and the remaining observations were used for interpolation. The procedure was repeated consecutively for all measured sites and the interpolation errors were calculated as the difference between the modeled and the observed values. The CV errors were used to calculate descriptive statistics, including: mean bias (BIAS), the root mean square error (RMSE), the mean absolute error (MAE), maximum and minimum errors

Table 4. Characteristics and important parameters of the spatialization

\begin{tabular}{|c|c|c|}
\hline Method & Characteristics & Important parameters \\
\hline IDW & $\begin{array}{l}\text { Deterministic } \\
\text { Exact } \\
\text { Local }\end{array}$ & $\begin{array}{l}\text { Power: } 2 \\
\text { 'Cut-off' distance: } 6000 \mathrm{~m}\end{array}$ \\
\hline RST & $\begin{array}{l}\text { Deterministic } \\
\text { Inexact } \\
\text { Global }\end{array}$ & $\begin{array}{l}\text { Tension: } 40 \\
\text { Smoothing: } 0.1\end{array}$ \\
\hline OK & $\begin{array}{l}\text { Stochastic } \\
\text { Exact } \\
\text { Local }\end{array}$ & $\begin{array}{l}\text { Semivariogram model: spherical } \\
\text { Range and sill fitted automatically }\end{array}$ \\
\hline MLR & $\begin{array}{l}\text { Deterministic } \\
\text { Inexact } \\
\text { Global } \\
\text { Multidimensional }\end{array}$ & $\begin{array}{l}\text { Case-dependent explanatory } \\
\text { variables (Table } 3 \text { ) }\end{array}$ \\
\hline RK & $\begin{array}{l}\text { Deterministic-stochastic } \\
\text { Exact } \\
\text { Global } \\
\text { Multidimensional }\end{array}$ & $\begin{array}{l}\text { Case-dependent explanatory } \\
\text { variables (Table } 3 \text { ) } \\
\text { Semivariogram model: spherical } \\
\text { Range and sill fitted automatically }\end{array}$ \\
\hline
\end{tabular}
methods used 
(Willmott \& Matsuura 2006). The statistical distribution of the $\mathrm{CV}$ errors was also characterized by skewness and kurtosis (Table 6). Statistical validation of the interpolation algorithms was complemented by visual analysis of the UHI spatial patterns. To allow comparison of results between the UHI cases, the CV errors were standardized (see Figs. 5 to 7 ).

\section{RESULTS AND DISCUSSION}

The first step in implementing multidimensional spatialization techniques is the selection of the most significant predictors and the determination of the linear regression coefficients ( $\beta$ ) using stepwise regression as described above (Table 5).

The most valuable explanatory variables for the UHI cases studied were NDVI, $z_{0}, \mu$ and $Q_{A}$ (Table 5). The statistical significance of AS in winter was also noticeable, suggesting seasonal changes in the importance of predictors. Residual standard errors change from 0.41 to $1.14^{\circ} \mathrm{C}$ and increase with the magnitude of the UHI (and therefore with spatial variability of the UHI phenomenon; Table 2). The $\mathrm{R}^{2}$ values show that depending on the case, 66 to $81 \%$ of the air temperature variance was explained by the regression model.

Based on statistical analysis of the CV errors, the RK can be selected as the most accurate method for spatial interpolation of the UHI in the 5 cases analysed (Table 6). For 2 UHI cases (15 Jan 2002 and 15 Feb 2002), better results (i.e. the smallest CV errors) were obtained using the OK. In general, least accurate results (the largest CV errors) were obtained with the IDW and MLR methods (Table 4, Fig. 4). However, the MLR algorithm usually gives significantly smaller values of BIAS compared with IDW. This suggests that IDW has a strong tendency to overestimate air temperature.

Three UHI cases from the set of 7 are illustrated on maps representing 3 groups of UHI generated under various wind conditions, which was found to be important for the spatialization results:

(1) UHI generated during weak winds, with UHI circulation (22 May 2001; Table 2, Fig. 5)
Table 5. Regression analysis results for the MLR and RK spatialization

\begin{tabular}{|llccc|}
\hline Date & $\begin{array}{l}\text { Predictors included } \\
\text { (in order of } \\
\text { significance) }\end{array}$ & $\begin{array}{c}\text { Residual } \\
\text { SE } \\
\left({ }^{\circ} \mathrm{C}\right)\end{array}$ & $\mathrm{R}^{2}$ & $\begin{array}{c}F \\
(\mathrm{n}=206)\end{array}$ \\
\hline 22 May 2001 & NDVI, $z_{0}, Q_{A}$ & 0.98 & 0.77 & 224.8 \\
26 Jun 2001 & $z_{0}, \mathrm{NDVI}, \mu$ & 0.77 & 0.81 & 214.5 \\
30 Jul 2001 & $z_{0}, \mu, \mathrm{NDVI}, Q_{A}$ & 1.01 & 0.69 & 110.4 \\
13 Oct 2001 & $z_{0}, \mu, Q_{A}, \mathrm{NDVI}$ & 0.80 & 0.72 & 135.4 \\
03 Jan 2002 & $Q_{A}, \mathrm{AS}, \mathrm{NDVI}$ & 1.14 & 0.66 & 134.8 \\
15 Jan 2002 & $\mu, \mathrm{NDVI}, \mathrm{NS}, \mathrm{AS}$ & 0.41 & 0.74 & 119.4 \\
15 Feb 2002 & $\mathrm{NDVI}, \mathrm{AS}$ & 0.75 & 0.69 & 228.0 \\
\hline
\end{tabular}

Table 6. Cross-validation results for the spatialization methods applied. BIAS: mean bias; MAE: mean absosulte error; RMSE: root mean square error

\begin{tabular}{|c|c|c|c|c|c|c|}
\hline Date & Statistic & IDW & RST & $\mathrm{OK}$ & MLR & RK \\
\hline \multirow{5}{*}{22 May 2001} & BIAS & 0.20 & 0.01 & 0.01 & 0.00 & 0.00 \\
\hline & MAE & 0.76 & 0.63 & 0.58 & 0.78 & 0.53 \\
\hline & RMSE & 1.01 & 0.86 & 0.79 & 0.99 & 0.68 \\
\hline & Skewness & 0.55 & 0.46 & 0.50 & 0.06 & 0.28 \\
\hline & Kurtosis & 3.27 & 4.50 & 4.26 & 2.95 & 3.40 \\
\hline \multirow[t]{5}{*}{26 Jun 2001} & BIAS & 0.19 & 0.00 & 0.01 & 0.00 & 0.01 \\
\hline & MAE & 0.68 & 0.54 & 0.51 & 0.61 & 0.46 \\
\hline & RMSE & 0.86 & 0.71 & 0.66 & 0.78 & 0.59 \\
\hline & Skewness & 0.40 & 0.39 & 0.32 & 0.04 & 0.39 \\
\hline & Kurtosis & 2.86 & 3.54 & 3.44 & 3.17 & 3.47 \\
\hline \multirow[t]{5}{*}{30 Jul 2001} & BIAS & 0.16 & 0.01 & 0.01 & 0.00 & 0.01 \\
\hline & MAE & 0.71 & 0.59 & 0.55 & 0.82 & 0.51 \\
\hline & RMSE & 0.92 & 0.77 & 0.72 & 1.02 & 0.68 \\
\hline & Skewness & 0.62 & 0.15 & 0.27 & 0.02 & 0.29 \\
\hline & Kurtosis & 3.03 & 3.53 & 3.62 & 2.84 & 3.45 \\
\hline \multirow[t]{5}{*}{13 Oct 2001} & BIAS & 0.14 & 0.00 & 0.01 & 0.00 & 0.00 \\
\hline & MAE & 0.60 & 0.48 & 0.46 & 0.62 & 0.46 \\
\hline & RMSE & 0.78 & 0.67 & 0.64 & 0.81 & 0.60 \\
\hline & Skewness & 0.38 & 0.45 & 0.74 & -0.16 & 0.15 \\
\hline & Kurtosis & 4.50 & 6.34 & 7.30 & 3.58 & 4.24 \\
\hline \multirow[t]{5}{*}{03 Jan 2002} & BIAS & 0.16 & 0.00 & 0.01 & 0.00 & -0.01 \\
\hline & MAE & 0.59 & 0.48 & 0.43 & 0.90 & 0.44 \\
\hline & RMSE & 0.78 & 0.62 & 0.56 & 1.15 & 0.54 \\
\hline & Skewness & 0.28 & 0.15 & 0.20 & -0.50 & 0.32 \\
\hline & Kurtosis & 3.63 & 3.46 & 3.53 & 3.08 & 2.58 \\
\hline \multirow[t]{5}{*}{15 Jan 2002} & BIAS & 0.06 & 0.00 & 0.01 & 0.00 & 0.00 \\
\hline & MAE & 0.27 & 0.21 & 0.20 & 0.34 & 0.22 \\
\hline & RMSE & 0.36 & 0.28 & 0.27 & 0.42 & 0.29 \\
\hline & Skewness & 0.47 & 0.24 & 0.34 & 0.00 & 0.10 \\
\hline & Kurtosis & 3.64 & 4.17 & 4.29 & 2.91 & 3.73 \\
\hline \multirow[t]{5}{*}{15 Feb 2002} & BIAS & 0.12 & -0.01 & 0.00 & 0.00 & 0.00 \\
\hline & MAE & 0.50 & 0.36 & 0.35 & 0.62 & 0.38 \\
\hline & RMSE & 0.62 & 0.46 & 0.45 & 0.76 & 0.48 \\
\hline & Skewness & 0.27 & 0.39 & 0.40 & 0.03 & 0.23 \\
\hline & Kurtosis & 2.95 & 3.75 & 3.60 & 2.77 & 3.31 \\
\hline
\end{tabular}


(2) UHI generated and shifted to the leeward side due to weak but stable regional winds (3 Jan 2002; Table 2, Fig. 6)

(3) UHI generated and 'generalized' under the influence of stronger winds (15 Jan 2002; Table 2, Fig. 7).

Two of these cases represent the strongest (22 May 2001, 3 Jan 2002) and one the weakest (15 Jan 2002)
UHI magnitude of all the cases analysed (Table 2). They also represent conditions of heating and nonheating seasons with different significant predictors (Table 5).

The CV technique allowed evaluation of the spatial tendency to over- or underestimate air temperature
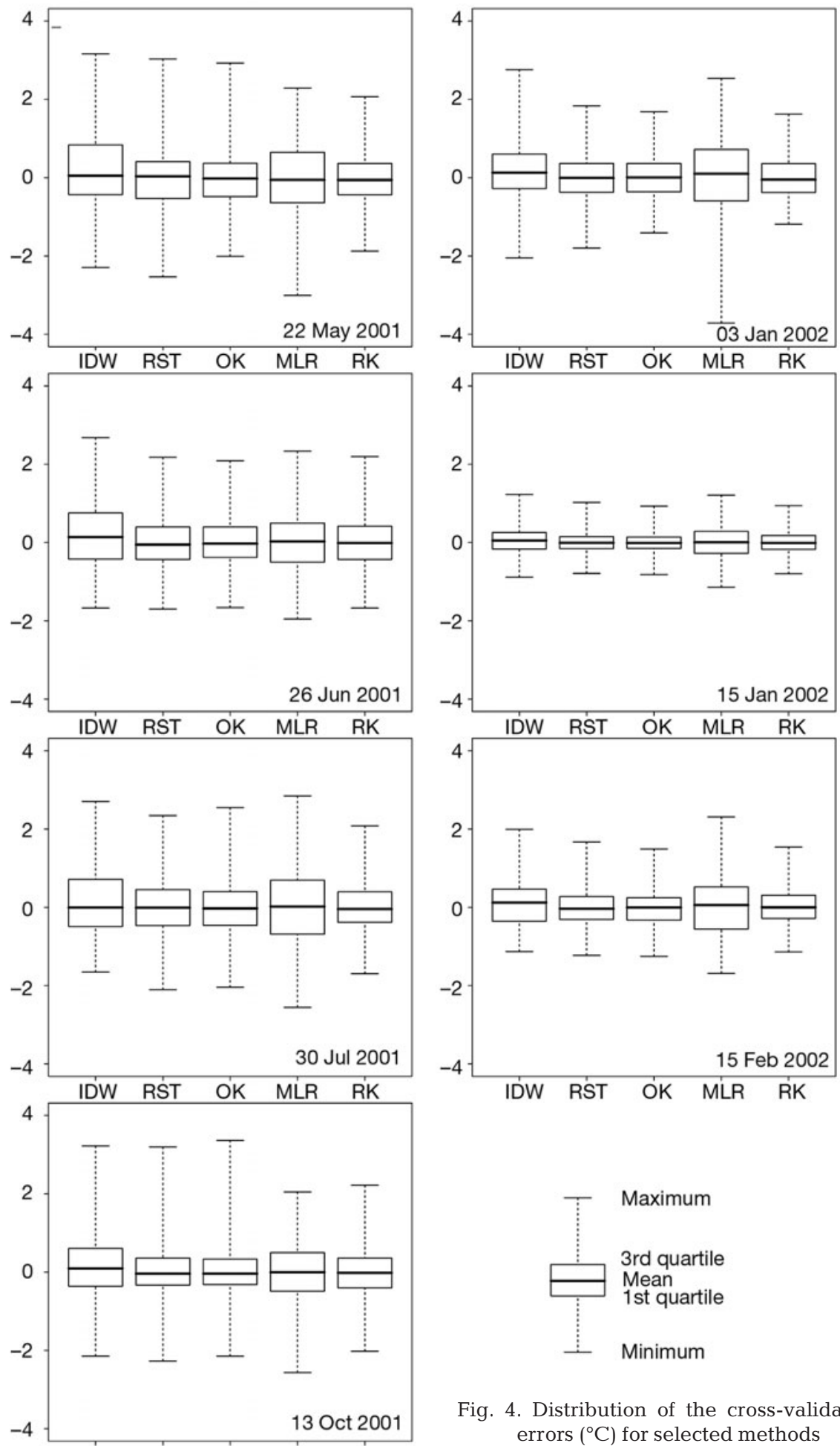

IDW RST OK MLR RK

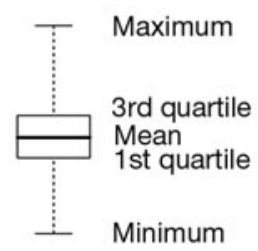

Fig. 4. Distribution of the cross-validation errors $\left({ }^{\circ} \mathrm{C}\right)$ for selected methods 

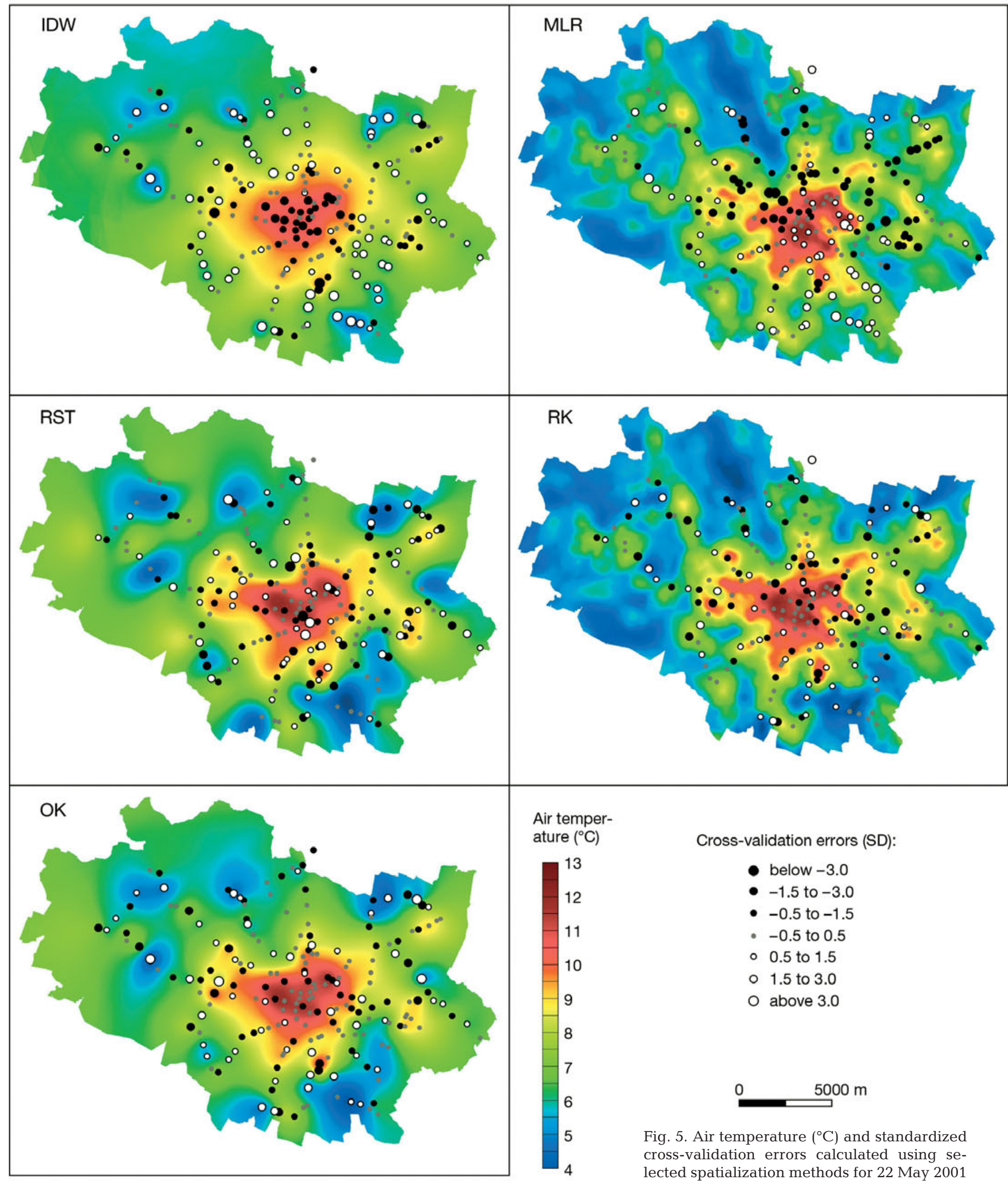

Air temperature $\left({ }^{\circ} \mathrm{C}\right)$

13
12
11
10
9
8
7
6
5
4

Cross-validation errors (SD):

- below -3.0

- -1.5 to -3.0

- -0.5 to -1.5

- -0.5 to 0.5

○ 0.5 to 1.5

- 1.5 to 3.0

O above 3.0

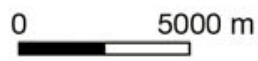

Fig. 5. Air temperature $\left({ }^{\circ} \mathrm{C}\right)$ and standardized cross-validation errors calculated using selected spatialization methods for 22 May 2001 

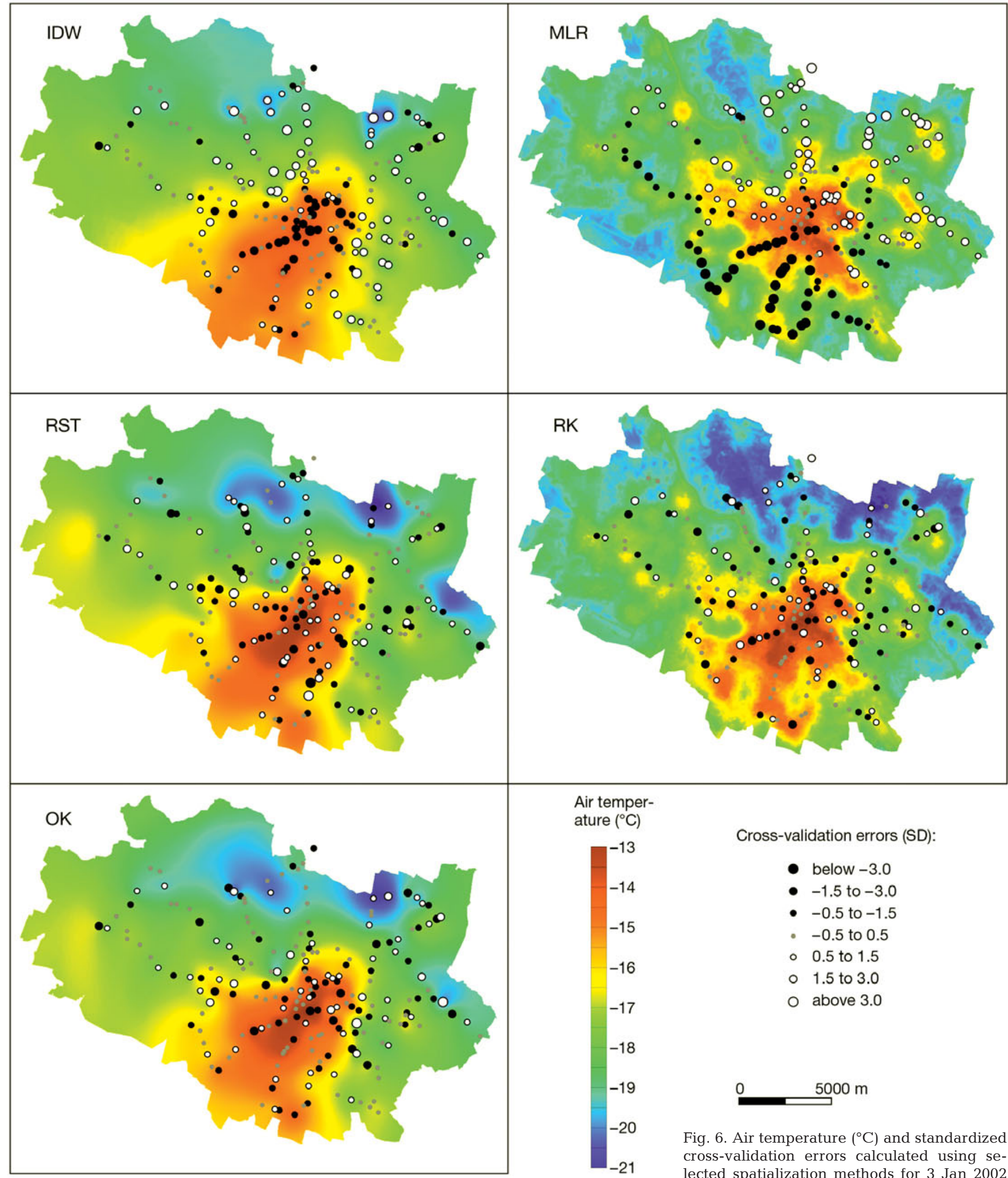

Air temperature $\left({ }^{\circ} \mathrm{C}\right)$

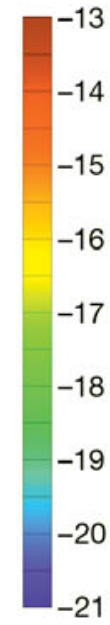

Cross-validation errors (SD):

- below -3.0

- -1.5 to -3.0

- -0.5 to -1.5

- -0.5 to 0.5

- 0.5 to 1.5

- 1.5 to 3.0

O above 3.0

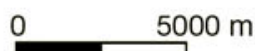

Fig. 6. Air temperature $\left({ }^{\circ} \mathrm{C}\right)$ and standardized cross-validation errors calculated using selected spatialization methods for 3 Jan 2002 

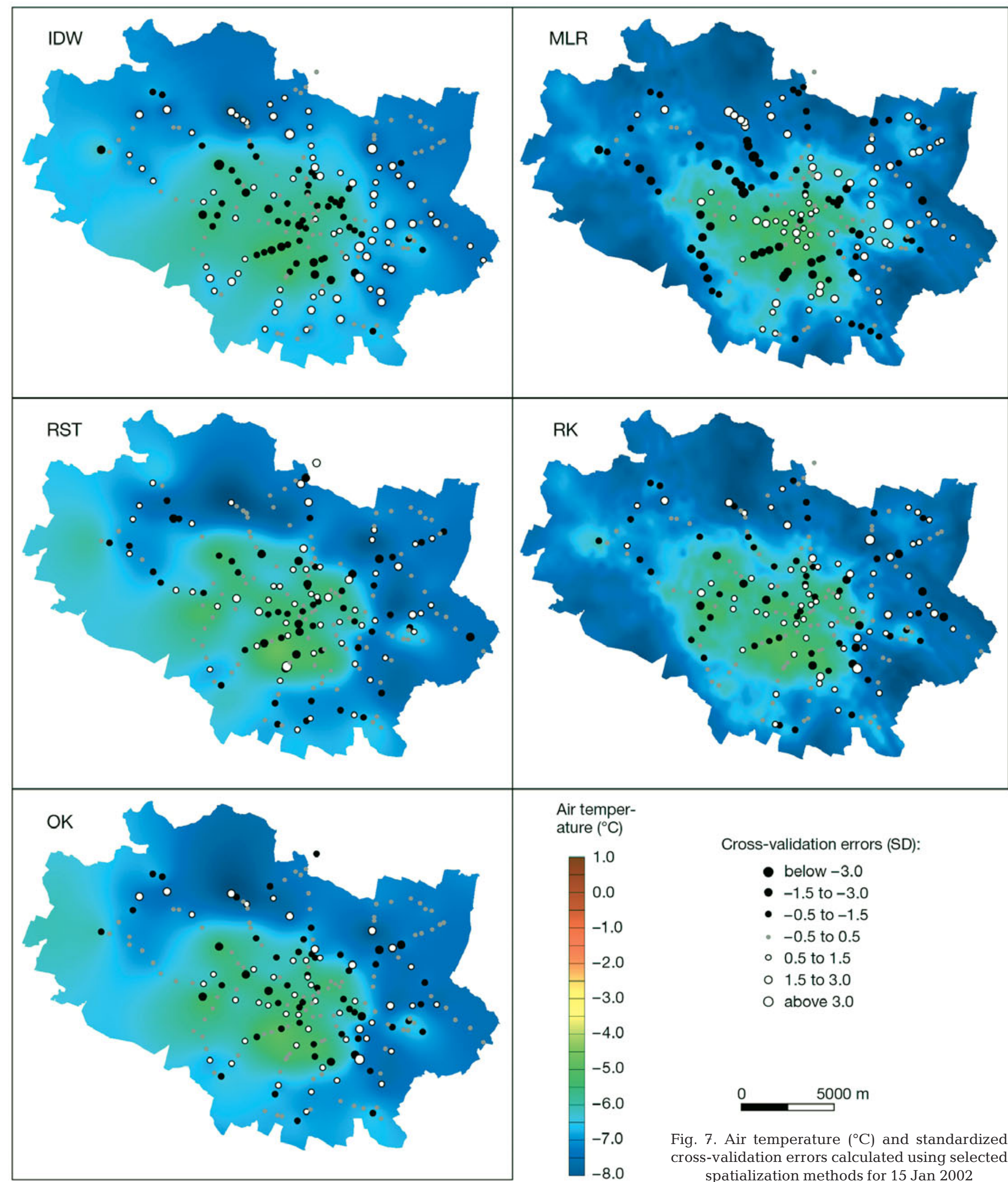

Air temper-

ature $\left({ }^{\circ} \mathrm{C}\right)$

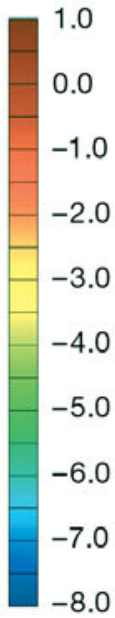

Cross-validation errors (SD):
- below -3.0
-1.5 to -3.0
- -0.5 to -1.5
- -0.5 to 0.5
- 0.5 to 1.5
o 1.5 to 3.0
O above 3.0

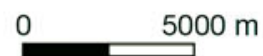

Fig. 7. Air temperature $\left({ }^{\circ} \mathrm{C}\right)$ and standardized cross-validation errors calculated using selected spatialization methods for 15 Jan 2002 
across the city. It is noticeable that the IDW algorithm consistently underestimated air temperature over the central parts of the city, despite the large positive BIAS that suggested overall overestimation. The MLR method tended to generate regular errors in different parts of the city, mostly in the cliff zone of the UHI (Figs. 5 to 7 ).

Spatial arrangement of the measured sites was of great importance for the interpolation results, especially for the simple distance-dependent algorithms. As a result, IDW, RST and OK produced an implausible pattern of air temperature outside the convex hull of points (Fig. 1). The predicted spatial pattern of temperature, in most cases, disagreed with the spatial arrangement of built-up and non-built-up areas, resulting in the overestimation of the temperature over the 'rural' outskirts of the city (Figs. 5 to 7). This means that the results were unrealistic in locations where extrapolation, not interpolation, was performed. These drawbacks characterize all methods that do not make use of auxiliary variables in the spatialization process. Inside the convex hull, all methods performed more or less correctly, except in the cliff zone of the UHI, where the CV errors are expected to be the largest. The same methods, especially the IDW, gave an unwanted 'bull's eye' effect, i.e. local extremes at the measurement site. The IDW can be considered as the least plausible of all tested methods that do not take advantage of additional explanatory variables. The other techniques of this group (RST, OK) were visually similar and more reliable in the convex hull area, although splines are not exact interpolators. The RST also gave larger CV errors than the OK, especially if MAE and RMSE were compared (Table 6, Fig. 4). Both methods showed a much more generalized spatial pattern of the UHI which can be useful for a preliminary study of the phenomenon but is of little use in more detailed investigations. This characteristic can be an advantage when wind speed is high enough to 'generalize' (Kłysik \& Fortuniak 1999) the spatial pattern of the UHI (Fig. 7). In such a case, the OK method can substitute multidimensional techniques inside the convex hull of points. However, when there is a need for detailed information on the UHI spatial structure, the multidimensional methods should be used.

The CV results suggest that the MLR method usually gives poorer outcomes than the OK (Table 6). The main advantage of the MLR is that the results are urbanbased and visually more realistic, even in places where extrapolation is performed, i.e. outside the convex hull. The MLR method of UHI spatialization has been applied with different sets of explanatory variables by Bottyán \& Unger (2003), Szymanowski (2004), Alcoforado \& Andrade (2006) and Szymanowski \& Kryza (2006). In all cases in this study, however, only up to 80 to $90 \%$ of the variance in air temperature was explained, even in the most stable, calm and cloudless meteorological conditions; the $\mathrm{R}^{2}$ ranges from 0.66 to 0.81. Results suggest that the explanatory variables applied here may not be precise enough or do not sufficiently describe all physical processes that are responsible for the formation of the UHI. This should be investigated in the future, and additional explanatory variables should be evaluated, especially for $z_{0}$ length (e.g. by using the more accurate Raupach [1994] approach instead of the simplified Lettau [1969] formula [Grimmond \& Oke 1999]). Other morphometric factors, including SVF and height to width ratio of the urban canyons should be applied (Bottyán \& Unger 2003, Alcoforado \& Andrade 2006). Part of the variance should also be explained by meteorological factors, especially wind speed and direction, which were not considered in the spatialization process here. Even if regional winds are not clearly strong, the influence of locally induced UHI circulation may affect the shape and magnitude of the UHI (Eliasson \& Holmer 1990). In such cases, part of the unexplained variance probably results from the unfulfilled assumption of the spatial process being stationary. This could be confirmed by analysis of the spatial distribution of $\mathrm{CV}$ residuals for the MLR method, which had the spatial tendency to over- or underestimate air temperature in some parts of the city (Figs. 5 to 7 ). This was clearly noticeable in the case of 3 Jan 2002 when the MLR model underestimated air temperatures in the SW part of the city but overestimated those in the NE part. In this case, the whole thermal 'cell' of the UHI was shifted to the SW due to weak but stable NE winds. This drift was recognized by all methods except the MLR, which assumes constant relationships with land-use derivatives. The problem could also potentially be solved by using local regression models like moving window regression (Lloyd 2007) or geographically weighted regression (Fotheringham et al. 2002).

Thus, to preserve the detailed, urban-originated air temperature pattern and correct the inaccuracy of the MLR method, the RK algorithm, which incorporates both deterministic and stochastic components, is recommended. This multidimensional algorithm, supported by physically meaningful environmental variables, gives the most reliable spatial pattern of the UHI with cliff, plateau and peak zones, together with a clear spatial drift.

\section{SUMMARY}

Based on the results for the 7 cases of the UHI in Wrocław, it can be concluded that of the 5 methods of spatial interpolation that were compared (IDW, RST, OK, MLR and RK), the IDW method produced the least 
reliable results and, consequently, the least accurate maps. This method is characterized by the largest CV errors and a strong tendency to generate the so-called 'bull's-eye' effect, and is therefore both statistically and visually unreliable. The 'bull's-eye' effect was not as clearly visible in the 2 other distance-based algorithms, RST and OK. Generally, the RST and OK gave similar results, which may be considered acceptable, albeit generalized, within the convex hull area of the sampling points. Outside the convex hull, where extrapolation, not interpolation was performed, these methods were not adequate.

Introduction of physically meaningful environmental variables for the MLR improves the quality of the maps, despite the usually worse CV results for the MLR than for the OK and the RST. Reflecting different land-use characteristics, this approach gives a more realistic UHI spatial pattern compared to the 'geometric' spatialization algorithms IDW, RST, OK. From the set of potential predictors; NDVI, $z_{0}, \mu$ and $Q_{A}$ are of great significance for the UHI cases studied. These results are especially important considering that some Central and Eastern European cities are still missing detailed and up-to-date spatial information on buildings geometry, which is needed to calculate, e.g. sky view factor. The parameters included in the present MLR model explained 66 to $81 \%$ of the air temperature variance, suggesting that part of the variance may be explained by other factors or that the spatial process might not be stationary. This situation may be caused by specific meteorological conditions, especially by winds that can generalize or shift the whole UHI 'cell' leeward. The problem is solved in the RK by adding the OK-spatialized regression residuals (stochastic part) to the regression-interpolated surface (deterministic part). In fact, meteorological conditions are treated here as a stochastic element. Such a procedure results in smaller CV errors in almost all cases and preserves spatial drift, retaining the land-use characteristics of the UHI. However, if the physical processes responsible for the UHI in a given case (wind for example) are known, effort should be made to include these at the first step of RK. This could probably improve both the MLR and RK CV statistics and make the models more robust and physically meaningful.

The methods presented here are intended for the spatialization of existing (measured) UHIs and should not be used to predict this phenomenon in the context of planning changes in land-use types or in other UHI drivers such as anthropogenic heat, albedo, etc. Nevertheless, it has been useful to show that the various interpolation schemes may result in different spatial patterns of UHIs. This may affect the results of modeling studies (e.g. urban pollution modeling), where information on air temperature is a key element.
Finally, we can conclude that the comparison of several interpolation algorithms in the case study of the UHI formed in a medium-sized city (Wrocław) located in a relatively flat terrain, shows the RK to be the most accurate spatialization technique.

Acknowledgements. The authors thank A. J. Dore and R. Kryza for their help in improving the manuscript.

\section{LITERATURE CITED}

Alcoforado MJ, Andrade H (2006) Nocturnal urban heat island in Lisbon (Portugal): main features and modelling attempts. Theor Appl Climatol 84:151-159

Boeker E, van Grondelle R (1995) Environmental physics. John Wiley \& Sons, Chichester

Bottyán Z, Unger J (2003) A multiple linear statistical model for estimating the mean maximum urban heat island. Theor Appl Climatol 75:233-243

Chudzia D, Dubicka M (1998) The spatial differentiation of anthropogenic heat emission in Wrocław (in Polish). Acta Univ Lodz. Folia Geogr Phys 3:295-305

Clarke JF, Peterson JT (1973) An empirical model using eigenvectors to calculate the temporal and spatial variations of the St. Louis heat island. J Appl Meteorol 12: $195-210$

COST719 WG2 (2006) Final report. Spatialization of climatological and meteorological information by the support of GIS (Final draft version 26.07.2006). http://cost719.met.no, Accessed 10 Oct 2007

Cressie NAC (1991) Statistics for spatial data. John Wiley \& Sons, New York

Dobesch H, Dumolard P, Dyras I (2007) Spatial interpolation for climate data: the use of GIS in climatology and meteorology. ISTE, London

Duckworth FS, Sandberg JS (1954) The effect of cities upon horizontal and vertical temperature gradients. Bull Am Meteorol Soc 35:198-207

Eliasson I, Holmer B (1990) Urban heat island circulation in Göteborg, Sweden. Theor Appl Climatol 42:187-196

Fortuniak K (2003) Miejska wyspa ciepła-podstawy energetyczne, studia eksperymentalne, modele numeryczne i statystyczne. Wydawnictwo Uniwersytetu Łódzkiego, Łódź

Fotheringham AS, Brunsdon C, Charlton C (2002) Geographically weighted regression. John Wiley \& Sons, Chichester

Gal T, Lindberg F, Unger J (2008) Computing continuous sky view factors using $3 \mathrm{D}$ urban raster and vector databases: comparison and application to urban climate. Theor Appl Climatol 95:111-123

GRASS Development Team (2007) Geographic Resources Analysis Support System (GRASS) Software. http://grass. itc.it. Accessed 6 Dec 2007

Grimmond CSB, Oke TR (1999) Aerodynamic properties of urban areas derived from analysis of surface form. J Appl Meteorol 38:1262-1292

Haeger-Eugensson M, Holmer B (1999) Advection caused by the urban heat island circulation as a regulating factor on the nocturnal urban heat island. Int J Climatol 19:975-988

Hurvich CM, Simonoff JS, Tsai CL (1998) Smoothing parameter selection in nonparametric regression using an improved Akaike information criterion. J R Stat Soc [Ser A] 60:271-293

Jauregui E (1986) The urban climate of Mexico City. Proc WMO Tech Conf 652, World Meteorological Organization, 


\section{Geneva}

Johnson GT, Watson ID (1984) The determination of viewfactors in urban canyons. J Clim Appl Meteorol 23:329-335

Kłysik K, Fortuniak K (1999) Temporal and spatial characteristics of the urban heat island of Eódź, Poland. Atmos Environ 33:3885-3895

Kuttler W (1993) Planungsorientierte Stadtklimatologie. Aufgaben, Methoden, Fallbeispiele. Geogr Rundsch 45:95-106

Kuttler W, Barlag AB, Robmann F (1996) Study of the thermal structure of a town in a narrow valley. Atmos Environ 30:365-378

Lettau H (1969) Note on aerodynamic roughness parameter estimation on the basis of roughness element description. J Appl Meteorol 8:828-832

Lindberg F (2007) Modelling the urban climate using a local governmental geodatabase. Meteorol Appl 14:263-273

Lloyd CD (2007) Local models for spatial analysis. CRC Press, Boca Raton, FL

Middleton WEK, Millar FG (1936) Temperature profiles in Toronto. J Roy Astron Soc Can 30:265-272

Mitašova H, Mitaš L (1993) Interpolation by regularized spline with tension. I. Theory and implementation. Math Geol 25:641-655

Moreno-Garcia CM (1994) Intensity and form of the urban heat island in Barcelona. Int J Climatol 14:705-710

Ninyerola M, Pons X, Roure JM (2000) A methodological approach of climatological modelling of air temperature and precipitation through GIS techniques. Int J Climatol 20:1823-1841

Oke TR (1976) The distinction between canopy and boundarylayer urban heat islands. Atmosphere (Toronto) 14: 268-277

Oke TR (1982) The energetic basis of the urban heat island. Q J R Meteorol Soc 108:1-24

Oke TR (1987) Boundary layer climates, 2nd edn. Methuen, London

Oke TR (2004) Initial guidance to obtain representative meteorological observations at urban sites. IOM Report No.81, WMO/TD No. 1250, World Meteorological Organization, Geneva

Oke TR (2006) Towards better scientific communication in urban climate. Theor Appl Climatol 84:179-190

Oke TR, Johnson GT, Styen DG, Watson ID (1991) Simulation of surface heat island under ideal conditions at night. 2. Diagnosis of causation. Boundary-Layer Meteorol 56: 339-358

Park HS (1986) Features of the heat island in Seoul and its surrounding cities. Atmos Environ 20:1859-1866

Pebesma EJ (2004) Multivariable geostatistics in S: the gstat

Editorial responsibility: Helmut Mayer,

Freiburg, Germany package. Comput Geosci 30:683-691

Peppler A (1929) Das Auto als Hilfsmittel der meteorologischen Forschung. Zeitschrift für angewandte Meteorologie 46:305-308

Preston-Whyte RA (1970) A spatial model of an urban heat island. J Appl Meteorol 9:571-573

R Development Core Team (2007) R: a language and environment for statistical computing. R Foundation for Statistical Computing, Vienna. www.r-project.org. Accessed 15 Oct 2007

Ratti CF (2001) Urban analysis for environmental prediction. Department of Architecture, Darwin College, University of Cambridge

> Raupach MR (1994) Simplified expressions for vegetation roughness length and zero-plane displacement as functions of canopy height and area index. Boundary-Layer Meteorol 71:211-216

Runnalls KE, Oke TR (2000) Dynamics and controls of the near-surface heat island of Vancouver, British Columbia. Phys Geogr 21:283-304

Svensson MK, Eliasson I, Holmer B (2002) A GIS-based empirical model to simulate air temperature variations in the Göteborg urban area during the night. Clim Res 22: $215-226$

Szymanowski M (2004) The urban heat island in Wrocław (in Polish). Wydawnictwo Uniwersytetu Wrocławskiego, Wrocław

Szymanowski M (2005) Interactions between thermal advection in frontal zones and the urban heat island of Wrocław, Poland. Theor Appl Climatol 82:207-224

Szymanowski M, Kryza M (2006) Evaluation of selected spatialisation techniques in urban heat island estimation. 6th Int Conf Urban Climate. Preprints, Urban Climate Group, Department of Geosciences, Goeteborg University, p 435-438

- Tucker CJ (1979) Red and photographic infrared linear combinations for monitoring vegetation. Remote Sens Environ $8: 127-150$

> Unger J, Sümeghy Z, Zoboki J (2001) Temperature crosssection features in an urban area. Atmos Res 58:117-127

> Ustrnul Z, Czekierda D (2005) Application of GIS for the development of climatological air temperature maps: an example from Poland. Meteorol Appl 12:43-50

Vicente-Serrano SM, Cuadrat-Prats JM, Saz-Sánchez MA (2005) Spatial patterns of the urban heat island in Zaragoza (Spain). Clim Res 30:61-69

Willmott CJ, Matsuura K (2006) On the use of dimensioned measures of error to evaluate the performance of spatial interpolators. Int J GIS 20:89-102

Submitted: March 10, 2008; Accepted: October 16, 2008 Proofs received from author(s): February 3, 2009 